\title{
CONCEITOS DE INFORMAÇÃO E SOCIEDADE DA INFORMAÇÁO E SUA IMPORTÂNCIA
}

INFORMATION AND INFORMATION SOCIETY CONCEPTS AND ITS RELEVANCE

\author{
BEATRIZ MARTINS DE OLIVEIRA ${ }^{1}$ \\ RICARDO LIBEL WALDMAN ${ }^{2}$
}

\section{RESUMO}

Em que pese a terminologia diuturnamente se popularizar, Sociedade da Informação ainda é um conceito para muitos inexplorado. A inexatidão do termo para alguns, dentre outros problemas casuísticos, decorre da incerteza que paira sobre o conceito de "informação". Assim, este artigo busca, de forma não exaustiva, considerada a profundidade da matéria a ser abordada, estudar e estabelecer qual o significado de "informação" para a Sociedade da Informação, se utilizando de uma visão multidisciplinar e pesquisa bibliográfica, para que também possamos conceituar Sociedade da Informação e demonstrar a importância de seu estudo na sociedade atual.

Palavras chave: Informação. Sociedade da Informação. Conceito.

\section{ABSTRACT}

In spite of the terminology becoming popular, Information Society still is an unexplored concept for many. The inaccuracy of the term for some, among other situational problems, stems from the uncertainty that hangs over the concept of "information". Therefore, this paper aims, in an not exhaustively way, considering the depth of the matter to be approached, study and establish what is the concept of "information" to Information Society, through a multidisciplinary view and bibliography research, so we are able to concept also Information Society and demonstrate the study's relevance to current society.

Key-words: Information. Information Society. Concept.

1 Mestranda em Direito da Sociedade da Informação pelo Centro Universitário das Faculdades Metropolitanas Unidas, especialista em Direito Processual Civil e bacharel em Direito pela mesma instituição. Advogada. ORCID iD: https://orcid. org/0000-0003-2314-1562. E-mail: beatriz.moliveira@outlook.com.

2 Doutor em Direito pela UFRGS. Coordenador e professor do Mestrado em Direito da Sociedade da Informação da Faculdades Metropolitanas Unidas e Professor da Escola de Direito da PUC-RS. Membro da Comissão de Direito Ambiental da IUCN. Lattes: http://lattes.cnpq.br/5138875442525636. E-mail: ricardo.waldman@fmu.br. 


\section{INTRODUÇÃO}

A fluidez da modernidade é um problema que atinge, inclusive, os conceitos. Comumente as palavras são empregadas quase como se tivessem perdido sua etimologia, se adequando a diversos discursos. Essa fluidez, talvez decorrente da inexatidão ou mesmo do desconhecimento conceitual, é um problema que assola diversas áreas do conhecimento científico, não sendo diferente com o estudo de "informação".

Em que pese se referir a algo que tenha conteúdo, a palavra "informação", paradoxalmente, cada vez mais tem perdido o seu sentido, levando pesquisadores a se dedicarem à sua conceituação. Mas, até por consequência lógica, mais incerteza paira quando a observamos no termo "Sociedade da Informação".

Neste contexto de pesquisas, não raras vezes, nos deparamos com livros ou artigos científicos que ultrapassam a conceituação dos temas, quase pressupondo que o leitor saiba o que é a Sociedade da Informação ou a qual "informação" este nome se refere. Tais pesquisas se iniciam sem abordar questões basilares, deixando o leitor novo na temática à deriva em conteúdos mais profundos e apenas permitindo sua real compreensão ao leitor já anteriormente familiarizado com o tema.

Cientes dessa questão, nos propomos neste trabalho a reunir estudos multidisciplinares com a finalidade de conceituar "informação", subsidiando, também, a conceituação de Sociedade da Informação, que, enquanto momento que vivenciamos e área de estudo, com suas próprias características e resultados, merece atenção. Ao final destacamos a importância da pesquisa para a sociedade atual e futura.

A pesquisa se divide em três capítulos. O primeiro analisa conceitos de "informação" através dos prismas da Ciência da Informação e do estudo direcionado da Sociedade da Informação, momento em que contamos com estudos das áreas da sociologia, economia, história e filosofia. O segundo se dedica ao conceito de Sociedade da Informação, considerando todo o referencial abordado no capítulo anterior. 0 terceiro aponta algumas situações que nos permitem perceber a importância dos estudos dos capítulos anteriores. Este artigo utiliza a metodologia de pesquisa bibliográfica.

\section{CONCEITOS DE INFORMAÇÃO}

A inexatidão do conceito de "informação" é uma preocupação de alguns campos do saber, o que tem levado diversos pesquisadores à tentativa de sua definição. Michael Buckland Keeble, por exemplo, afirmou que 'Uma exploração de 'informação' encontra imediatas dificuldades. Como informação se relaciona com se tornar informado, com redução da ignorância e incerteza, é irônico que o próprio termo 'informação' seja ambíguo e usado de diferentes formas." ${ }^{3}$ (BUCKLAND, 1991, p. 351).

3 "An exploration of 'information' runs into immediate difficulties. Since information has to do with become informed, with the reduction of ignorance and of uncertainty, it is ironic that the term "information" is itself ambiguous and used in different ways." - Tradução livre. 
De igual forma, mais especificamente no campo de estudo da Sociedade da Informação, Mattelart (2006, p. 64) afirma que "Quanto à noção de 'informação', ela logo se transformará em caixa preta, palavra-mestra, verdadeiro 'Proteu da semântica' saído da 'caixa de Pandora dos conceitos imprecisos'", demonstrando igual preocupação quanto às diferentes maneiras com que a palavra tem sido aplicada, formas que até surpreendem, razão pela qual o conceito merece atenção.

Destarte, considerando nosso objetivo final de estabelecer o conceito de "informação" para a Sociedade da Informação através de uma visão multidisciplinar, este primeiro capítulo se dedicará a analisar o conceito informacional pelas perspectivas da Ciência da Informação, bem como a partir do estudo da Sociedade da Informação.

\subsection{CONCEITO DE INFORMAÇÁO PARA A CIÊNCIA DA INFORMAÇÁO}

A Ciência da Informação é um campo de estudo que caminha de forma muito próxima ao estudo da Sociedade da Informação ${ }^{4}$, e que tem por objetivo analisar problemas informacionais, decorrentes da importante responsabilidade social de transmitir conhecimento (SARACEVIC, 1996, p. 43). Buckland, em um artigo que se dedicou exclusivamente a analisar o conceito de informação, estabelece a existência de três principais significados para a palavra: informação como processo, informação como conhecimento e informação como coisa (BUCKLAND, 1991, p. 351), analisando-os sob duas óticas: primeiro, se a informação é tangível ou intangível, e segundo, se é entidade ou processo (BUCKLAND, 1991, p. 352).

Para o autor, informação como processo é aquela que causa transformação no conhecimento da pessoa, é o recebimento de um novo conteúdo. É um processo intangível, independente de um suporte físico. Já informação como conhecimento é objeto do processo informacional, sendo preciso que seja expressa através de processos comunicacionais para que se faça conhecida. Nesta configuração, a informação é entidade intangível. Por outro lado, informação como coisa se refere ao documento manipulável que contém a informação como conhecimento, sendo este, por este motivo, uma entidade tangível (BUCKLAND, 1991, p. 351). Neste sentido:

A intenção pode ser que os usuários se tornem informados (informação como processo) e que ocorra uma transmissão de conhecimento (informação como conhecimento). Mas os meios fornecidos, o que é manuseado e operado, o que armazena e recupera, é informação física (informação como coisa). (BUCKLAND, 1991, p. 352). ${ }^{5}$

4 "Três são as características gerais que constituem a razão da existência e da evolução da Cl; outros campos compartilham-nas. Primeira, a Cl é, por natureza, interdisciplinar, embora suas relações com outras disciplinas estejam mudando. A evolução interdisciplinar está longe de ser completada. Segunda, a Cl está inexoravelmente ligada à tecnologia da informação. O imperativo tecnológico determina a $\mathrm{Cl}$, como ocorre também em outros campos. Em sentido amplo, o imperativo tecnológico está impondo a transformação da sociedade moderna em sociedade da informa ão, era da informa ão ou sociedade p s-industrial. Terceira, a Cl é, juntamente com muitas outras disciplinas, uma participante ativa e deliberada na evolução da sociedade da informação. A Cl teve e tem um importante papel a desempenhar por sua forte dimensão social e humana, que ultrapassa a tecnologia. Essas três características ou razões constituem o modelo para compreensão do passado, presente e futuro da $\mathrm{Cl}$ e dos problemas e questões que ela enfrenta." Fonte: SARACEVIC, Tefko. Ciência da informação: origem, evolução e relações. In Ci. Inf., Belo Horizonte, v. 1, n. 1, p. 42, jan./jun. 1996. Disponível em: http://portaldeperiodicos.eci. ufmg.br/index.php/pci/article/view/235/22 Acesso em: 09 de abril de 2020.

5 "The intention may be that users will become informed (information-as-process) and that there will be an imparting of knowledge (information-as-knowledge). But the means provided, what is handled and operated upon, what is stored and retrieved, is physical information (information-as-thing)." - Tradução livre. 
Portanto, o autor elenca três significados possíveis para a palavra "informação" no estudo da Ciência da Informação. Há, entretanto, outra abordagem possível, igualmente importante e complementar a essa análise, ainda nesta área de estudos. Rowley (2006, p. 163-180), cuja pesquisa compreende a chamada Hierarquia da Sabedoria (ou DKIW hierar$\left.c h y^{6}\right)$, que escalona dados, informação, conhecimento e sabedoria, servirá também de subsídio para fundamentar o conceito de "informação".

Segundo a autora (ROWLEY, 2006, p. 166), o primeiro registro do ideal hierárquico teria aparecido em um poema de T. S. Eliot, chamado The Rock, em 1934, em que o eu lírico questiona: "Onde está a sabedoria que perdemos no conhecimento? Onde está o conhecimento que perdemos na informação?"7. Entretanto, a hierarquia contendo todos seus objetos atuais (dados, informação, conhecimento e sabedoria), além de mais um (o entendimento, não utilizado frequentemente), seria atribuída a Ackoff em seu texto From data to wisdom, datado de 1989.

Analisando Ackoff (1999, p. 170), verificamos que ele inicia seu trabalho afirmando que "Um grama de informação vale um quilo de dados. Um grama de conhecimento vale um quilo de informação. Um grama de entendimento vale um quilo de conhecimento." ${ }^{8}$ e conceitua dados como símbolos que representam qualidades de objetos, enquanto informação seria o dado processado, aprimorado para garantir sua maior utilidade. Acrescenta o autor que, portanto, a diferença entre dados e informação é funcional, e não estrutural.

Apesar de Ackoff (1999, p. 170) ainda diferenciar informação de conhecimento e entendimento, afirmando que informação responde a perguntas como "quem", "o que" ou "quando" (descrições), enquanto conhecimento responde a perguntas de "como" (instruções) e entendimento às perguntas de "por que" (explicações), ele afirma que todos estes atuam de igual forma, aumentando a eficiência. Sabedoria, por sua vez, para o autor, está ligada a um juízo valorativo.

Rowley (2006, p. 176), analisando Ackoff e outros estudiosos acerca do conceito de informação, conclui que este último está constantemente relacionado ao conceito de dados, o que reacende nossa discussão neste artigo. As considerações deste capítulo, fincadas especificamente na Ciência da Informação, servirão à nossa próxima análise, que se restringirá ao conceito de informação para o estudo da Sociedade da Informação.

\subsection{INFORMAÇÁO PARA A SOCIEDADE DA INFORMAÇÁO}

Antes de conceituarmos Sociedade da Informação, observaremos a extensão semântica de "informação" para este conceito, a fim de melhor subsidiar os estudos. Desta forma, em que pese o uso constante do termo "Sociedade da Informação", focaremos apenas nas definições que encontramos neste campo para a informação, as quais corroborarão o estudo subsequente sobre a Sociedade da Informação.

6 Cunha para a hierarquia da sabedoria que alude às iniciais de dados, conhecimento, informação e sabedoria em inglês (data, knowlegde, informatione wisdom).

7 "Where is the wisdom that we have lost in knowledge? Where is the knowledge that we have lost in information?" - Tradução livre.

8 "An ounce of information is worth a pound of data. An ounce of knowledge is worth a pound of information. An ounce of understanding is worth a pound of knowledge." - Tradução livre. 
Mattelart, em uma análise histórica da Sociedade da Informação e a partir de diversos autores, traz possíveis definições para informação. Em um sentido matemático, cita a Teoria Matemática da Comunicação, de Claude Elwood Shannon, afirmando que a "definição da informação é estritamente física, quantitativa, estatística. Trata-se sobretudo de 'quantidade de informação'." (MATTELART, 2006, p. 63). E, contrapondo esta ideia, a partir de Machlup argumenta que, linguisticamente, informar é transmitir conhecimento (MATTELART, 2006, p. 69). Complementa, a partir do ponto de vista filosófico de Bernard Stiegler, que o valor da informação é ligado ao tempo de sua difusão, isto é, "a informação é uma mercadoria de memória perecível por definição; ela abre uma nova forma de temporalidade que forma um contraste com a do tempo de elaboração do saber" (MATTELART, 2006, p. 71). 0 autor relaciona o valor da informação ao seu tempo de difusão, pois, com o passar do tempo, ela se torna obsoleta, perde seu valor.

Por sua vez, Amaral (2008, p. 126), em um estudo com o enfoque econômico da Sociedade da Informação, esclarece que informação é "uma mensagem, geralmente sob a forma de um documento ou em uma comunicação audível e/ou visível numa versão enriquecida de dados, uma vez que inclui algo sobre o contexto que permita retirar algum significado".

Para Castells (2016, p. 135), pelo prisma sociológico, "A emergência de um novo paradigma tecnológico organizado em torno de novas tecnologias da informação, mais flexíveis e poderosas, possibilita que a própria informação se torne o produto do processo produtivo.", ou seja, o autor entende a informação como produto na Sociedade da Informação.

Especificamente no âmbito brasileiro, o Livro Verde da Sociedade da Informação, em sua apresentação (TAKAHASHI, 2000, p. v), em que pese empregar o termo "conhecimento" (que muitas vezes se confunde com "informação"), direciona o contexto para a compreensão do Livro, que trata sobre a Sociedade da Informação no Brasil, consignando que "O conhecimento tornou-se, hoje mais do que no passado, um dos principais fatores de superação de desigualdades, de agregação de valor, criação de emprego qualificado e de propagação do bem-estar." O conceito adotado carrega muitas características nas quais percebemos o fundo comum de agregar conhecimento ao receptor da mensagem, pois assim é que encontraremos a maioria destes pontos destacados. Outro fator que merece destaque no conceito está na agregação de valor, que nos remete a uma visão contributiva da informação como uma qualificadora que traz consigo valor.

Sampaio, analisando questões sobre o uso (escuso) de dados pessoais por grandes empresas e por governos, trata, de um prisma jurídico, sobre a necessidade de um sistema de proteção de dados mais eficaz, que veja este interesse como metaindividual, já que as consequências de seu uso ultrapassam a esfera do indivíduo, atingindo a coletividade. 0 autor afirma que:

[...] informação consiste em dados economicamente apreciáveis, que podem servir como recurso ou produto, podendo melhorar o desempenho de determinado agente de acordo com seu tratamento ou fornecimento a outrem, de modo que não se limita a uma informação fechada, completa. Sua importância, portanto, está mais associada ao seu uso e à sua finalidade que própria e necessariamente ao seu titular [...]. (grifo do autor) (SAMPAIO, 2019, p. 37).

O autor fala em "dados economicamente apreciáveis". Acerca disso, podemos destacar Harari, que analisa o valor dos dados. 0 autor explica que ao reunir informação, os gigantes 
dos dados poderão nos manipular, trabalhar com reengenharia da vida orgânica e criação de formas de vida inorgânica, destacando que, apesar de a publicidade os manter financeiramente a curto prazo, seu valor é avaliado através dos dados que possuem e colhem. $\mathrm{E}$ conclui seu pensamento, de forma a nos encaminhar a que, sim, informação se constitui de dados economicamente apreciáveis (agora ou em potencial), afirmando que:

Mesmo que não se saiba como fazer dinheiro com os dados hoje em dia, vale a pena tê-los porque eles podem ser a chave para controlar e modelar a vida no futuro. Não tenho certeza de que os gigantes dos dados pensam explicitamente nesses termos, mas suas ações indicam que dão mais valor aos dados acumulados do que a meros dólares e centavos. (HARARI, 2018, p. 108).

Diante de cada um dos estudos e conceitos apresentados, podemos atribuir à informação um conceito complexo para a Sociedade da Informação. Ainda que por vezes busquemos um conceito universal, aplicável para determinada palavra em qualquer contexto, em regra, isso não ocorrerá, de forma que não conceituaremos, assim, "informação" em um contexto coloquial, corriqueiro ou geral, mas especificamente para o estudo da Sociedade da Informação.

Os estudos levantados nos direcionam à conclusão de que "informação" para a Sociedade da Informação, em um sentido lato:

- é "informação como conhecimento", uma entidade intangível, pois, consoante Buckland (1991, p. 351), é efetivamente o conhecimento que é transmitido, o objeto da comunicação;

- referencia dados, informação, conhecimento e entendimento, uma vez que, conforme Ackoff (1999, p. 170), a diferença entre estas definições está em sua função e não em sua estrutura. Na medida em que um dado, informação etc. é trabalhado, adquire novas funções, ainda que sua estrutura seja compartilhada;

- é recurso, conforme Sampaio (2019, p. 37) destaca, pois a informação é utilizada para gerar mais informação;

- é produto do processo produtivo, como Castells (2016, p. 135) elucida, pois, ao mesmo tempo em que é recurso, é o objetivo final mercadológico, ou seja, é alvo de negociações;

- agrega e possui valor. Na apresentação do Livro Verde da Sociedade da Informação (TAKAHASHI, 2000, p. v) consta que o conhecimento agrega valor, sem informar a que ou a quem seria agregado. A informação, de forma complementar, pode agregar valor a produtos e serviços, e por esta razão, de forma individual, a ela será atribuído um valor;

- tem seu valor diretamente influenciado pelo tempo de sua propagação, porque com o passar do tempo a informação pode se tornar obsoleta, desinteressante, equivocada, sofrendo, portanto, influência direta do fator temporal (MATTELART, 2006, p. 71). A esta característica devemos somar, ainda, o fator das novas tecnologias que atribuem uma nova sensação temporal, diferente do tempo físico, e que proporciona novas informações a todo momento.

- possui valor futuro incerto, em potencial, decorrente do grande poder que pode conceder aos seus detentores, conforme Harari (2018, p. 108) explica.

E com este apanhado conceituamos. Informação é para a Sociedade da Informação uma entidade intangível, objeto de um processo informacional, comunicativo, que, em sentido 
lato, acolhe dados, informações, conhecimento e entendimento, na medida em que cada um destes termos possui a mesma estrutura, apesar de suas diferentes funções. A informação é recurso e produto final no processo produtivo, considerando-se que é utilizada para a produção de mais informação, tanto quanto é o resultado dessa produção. Possui valor mercadológico, financeiro, de forma independente, decorrente de sua capacidade de atribuir valor a produtos e serviços, o que pode ser aferido de formas diversas a depender do seu tempo de difusão. E possui um valor potencial, decorrente de seu uso futuro, ainda incerto na forma, mas certo no poder.

\section{SOCIEDADE DA INFORMAÇÃO}

Tendo conceituado informação, voltamos nossa preocupação à Sociedade da Informação, que, igualmente, por muitas vezes sofre com a indeterminação de seu conceito. Neste aspecto, Matellart (2006, p. 71) afirma que "A imprecisão que envolve a noção de informação coroará a de 'sociedade da informação'.". E, ainda, Webster (2006, p. 08) questiona:

O que impressiona na leitura da literatura sobre sociedade da informação é que muitos autores trabalham com definições não desenvolvidas de seu objeto. Parece-lhes tão óbvio que vivemos em uma sociedade da informação que alegremente presumem não ser necessário esclarecer precisamente o que querem dizer com o conceito. ${ }^{9}$

Tendo em mente esta outra problemática, trabalharemos com o conceito previamente estabelecido de "informação" e com as definições de alguns autores para conceituar Sociedade da Informação. Para tanto, iniciaremos com uma sucinta análise histórica, conforme o estudo de Crawford (1983, p. 380), que estabelece o início das pesquisas acerca da Sociedade da Informação no ocidente em 1962, com o economista Fritz Machlup, que estudou a produção de conhecimento nos Estados Unidos da América como importante componente para o Produto Interno Bruto.

Em que pese naquele momento ainda não observarmos o uso da expressão "Sociedade da Informação" - Machlup utiliza indústria do conhecimento -, é a partir dele que se verifica o estudo sobre as características da informação conforme nosso atual conceito. $\mathrm{E}$, logo após, na década de 1970, o termo Sociedade da Informação já passa a ser empregado (CRAWFORD, 1983, p. 381).

Além do termo utilizado por Machlup, podemos destacar muitos outros que foram utilizados para referenciar a sociedade que deixaria para trás a indústria material como base de sua economia. Masi (2003, p. 32), que prefere o termo "sociedade pós-industrial", atribui essa grande variedade à incerteza que pairou em determinado momento acerca de qual característica predominaria na sociedade que se estabelecia a seguir, sobre o que substituiria a indústria de capital material:

9 "What strikes one in reading the literature on the information society is that so many writers operate with undeveloped definitions of their subject. It seems so obvious to them that we live in an information society that they blithely presume it is not necessary to clarify precisely what they mean by the concept". - Tradução livre. 
Os rótulos atribuídos à sociedade atual, aos estágios evolutivos da transição e às sociedades auspiciadas são mais de trezentos e vão desde "sociedade em impasse" (M. Crozier) e "sociedade despreparada" (D. Michael), a "idade do equilíbrio" (L. Mumford), a "consciência III" (C. Reich), a "século casual" (M. Harrington), a "estado de entropia" (H. Henderson), a "sociedade narcisista" (Ch. Lasch), a "sociedade programada" (A. Touraine e Z. Hegedus), a "sociedade pós-moderna" (J. F. Lyotard), a "cultura pré-figurativa" (M. Mead), a "sociedade pós-civil" (K. Boulding). E temos ainda a "sociedade pós-capitalista" de R. Dahrendorf, a "sociedade do capitalismo maduro" de C. Offe, a "sociedade do capitalismo avançado" de K. Galbraith, a "sociedade sadia" de E. Fromm, a "sociedade ativa" de A. Etzioni, a "sociedade pós-materialista" de R. Inglehart, a "sociedade tecnotrônica" de Z. Brzezinski, a "terceira onda" de Toffler, a "sociedade dos serviços" de J. Gershuny e W. R. Rosengren, a "era da descontinuidade" de Drucker. (MASI, 2003, p. 33)

Por outro lado, no Oriente, o termo Sociedade da Informação apareceu um pouco mais cedo. Segundo Karvalics (2007, p. 05), em 1961, o termo teria sido empregado durante uma conversa entre o arquiteto Kisho Kurokawa e o historiador e antropologista Tudao Umesao, no Japão. E, de forma escrita, teria aparecido pela primeira vez em um estudo publicado por Jiro Kamishima em janeiro de 1964, intitulado pelo editor Michiko Igarashi como Sociologia nas Sociedades da Informação. Não muito mais tarde, nos anos de 1968 e 1969, já existiam no país livros que trabalhavam a temática utilizando-se especificamente deste termo.

Tendo vista este panorama histórico contextualizando nossa análise, que demonstra que os estudos da Sociedade da Informação no Ocidente surgiram de um estudo econômico do saber, destacamos alguns conceitos que demonstram essa relação da informação com a economia e que nos permitem compreender que vivenciamos o momento histórico em que a base econômica industrialista material foi deixada para trás, dando lugar a uma nova base econômica intangível: a informação.

Cumpre esclarecer, conforme Mattelart, que, considerando o avanço tecnológico, há uma preocupação da visão limitada da "informação" como conceito dependente da tecnologia, pois, desta forma, o conceito de Sociedade da Informação se tornaria puramente instrumental. Apesar de as novas tecnologias terem trazido grandes mudanças para a Sociedade da Informação, devemos ter por certo que um conceito independe do outro.

A tendência a assimilar a informação a um termo proveniente da estatística (data/dados) e a ver a informação somente onde há dispositivos técnicos se acentuará. Assim, instalar-se-á um conceito puramente instrumental de sociedade da informação. Com a atopia social do conceito apegar-se-ão as implicações sociopolíticas de uma expressão que supostamente designa o novo destino do mundo. (MATTELART, 2006, p. 71)

Feita essa ressalva, avançamos na busca pelo conceito de Sociedade da Informação, referenciando alguns autores. Loveluck afirma que "À sociedade da informação corresponderia, assim, uma 'economia do conhecimento' ou 'economia do saber', que seria a sequência do 'capitalismo industrial'" (LOVELUCK, 2018, p. 112), indicando - como também outros autores preferem referenciar - uma sociedade pós industrial (MASI, 2003, p. 93). Aprofundando a visão para além das questões econômicas, Amaral entende que a Sociedade da Informação implica alterações sociais e econômicas:

Do ponto de vista tecnológico a Sociedade da Informação constitui um aprofundamento das tecnologias das tecnologias electrónicas e da revolução 
digital da $3^{\text {a }}$ Revolução Industrial, mas do ponto de vista sócio-económico é muito mais do que isso. A Sociedade da Informação traz um novo modelo de desenvolvimento económico ao mesmo tempo que provoca profundas e extensas alterações nos comportamentos, nas atitudes e nos valores das estruturas sociais e políticas do nosso tempo. (AMARAL, 2008, p. 41)

Bioni, por sua vez, entende esta sociedade como a que tem por seu elemento nuclear a informação:

No estágio atual, a sociedade está encravada por uma nova forma de organização em que a informação é o elemento nuclear para o desenvolvimento da economia, substituindo os recursos que outrora estruturavam as sociedades agrícola, industrial e pós-industrial. (BIONI, 2019, p. 02)

Por outro lado, devemos considerar o caráter global que a Sociedade da Informação possui. Conforme analisa Branco, deve haver uma cooperação entre os países para que possamos, de fato, alcançar a Sociedade da Informação em nível mundial, ao passo que, na concepção do autor, um relacionamento entre os países que não possibilita a troca de informações caracteriza uma "sociedade da desinformação". (BRANCO, 2005, p. 234).

Acerca do sentido lato de Sociedade da Informação, Himanen destaca que "De uma perspectiva teórica, o conceito-chave inclui uma organização em rede ${ }^{10} \mathrm{e}$ o crescimento baseado na inovação. A economia da informação assenta no crescimento da produtividade baseado na inovação, ao contrário da chamada «nova economia»." (HIMANEN, 2005, p. 347).

A partir destes referenciais teóricos temos, portanto, que a Sociedade da Informação é o momento histórico, de caráter global, organizado em rede, que tem a informação como seu cerne e no qual a economia e as relações sociais foram reestruturadas tendo sua base na informação, sendo que tal momento, apesar de não depender das novas tecnologias, tem suas características potencializadas por elas, descansando atualmente nelas sua base operacional.

Somando a esta análise nosso prévio conceito de informação, conceituamos Sociedade da Informação como sendo o momento histórico econômico-social em que a entidade intangível que é o objeto do processo comunicacional, isto é, a informação como conhecimento, é o meio e o fim das relações mercadológicas, pois ela se apresenta como recurso e como produto. Neste período, a informação é capaz de atribuir valor, que será cotejado de diferentes formas em diferentes contextos temporais, sendo que as relações (organizadas em rede), assim como a economia, passam a ter caráter global, cujas bases repousam nas novas tecnologias da informação.

10 "Além disso, a comunicação em rede transcende fronteiras, a sociedade em rede é global, é baseada em redes globais. Então, a sua lógica chega a países de todo o planeta e difunde-se através do poder integrado nas redes globais de capital, bens, serviços, comunicação, informação, ciência e tecnologia. Aquilo a que chamamos globalização é outra maneira de nos referirmos à sociedade em rede, ainda que de forma mais descritiva e menos analítica do que o conceito de sociedade em rede implica. Porém, como as redes são selectivas de acordo com os seus programas específicos, e porque conseguem, simultaneamente, comunicar e não comunicar, a sociedade em rede difunde-se por todo o mundo, mas não inclui todas as pessoas. De facto, neste início de século, ela exclui a maior parte da humanidade, embora toda a humanidade seja afectada pela sua lógica, e pelas relações de poder que interagem nas redes globais da organização social." Fonte: CASTELLS, Manuel. A Sociedade em Rede: do Conhecimento à Política. In A Sociedade em Rede Do Conhecimento à Acção Política. Portugal, Imprensa Nacional - Casa da Moeda, 2005, p. 18. 


\section{A RELEVÂNCIA DA CONCEITUAÇÃO: ALGUNS USOS DA INFORMAÇÃO NA SOCIEDADE DA INFORMAÇÃO}

A conceituação de termos pode parecer apenas interessante do ponto de vista acadêmico, mas se revela muito importante em um aspecto prático. Os conceitos nos permitem analisar questões da vida diária com novos prismas, sendo exatamente o que este último capítulo busca demonstrar de uma forma apenas pincelada, pois seu estudo de maneira detida proporcionaria uma pesquisa exclusiva e mais extensa.

Considerando o conceito de informação para o estudo da Sociedade da Informação, que a contempla como produto final e recurso no processo produtivo, possuindo valor mercadológico real e potencial, a conclusão (ainda não expressamente adotada neste estudo, mas mesmo assim decorrente dele) é que o detentor dessa informação em massa possui muito poder, seja ele atual, na forma de recursos financeiros, ou potencial, em formas a se revelar.

Harari $(2018$, p. 108) trabalha muito bem essa relação. O autor tece considerações acerca dos gigantes dos dados - as grandes empresas detentoras de incontáveis dados, sobre incontáveis pessoas -, ponderando que seu sustento atual, realizado através da publicidade (venda de informações sobre consumidores para agregar valor às práticas de publicidade, que origina o consumidor de vidro (BIONI, 2019, p. 19)), pouco se compara ao poder que elas têm acumulado com esses dados para o futuro, que hoje são utilizados com finalidade menor e passageira.

Mesmo ao pensarmos no uso dessas informações nesse contexto "inocente" (perto das demais práticas que apontaremos) de manipulação, ela mesma se torna ameaçadora para além do consumismo. Voltando-nos ao sistema democrático, Harari $(2018$, p. 110) recorda o escândalo da Cambridge Analytica ${ }^{11}$, demonstrando que, além da mera especulação, a democracia sofre real ameaça por esse poder alcançado por quem detém informação. A propaganda direcionada, as fake news, todas as formas empregadas para manipular as pessoas através da informação acabam por manipular o sistema "democrático".

Para o autor, ainda, esses dados em um período futuro poderão propiciar a manipulação da vida orgânica ou a criação de vida inorgânica, além de outras possibilidades que sequer podemos imaginar. Esse poder - que em nossa pesquisa intitulamos como valor potencial da informação -, que parece até divino, diz Harari, está monopolizado nas mãos das gigantes dos dados. E questiona: seria melhor conceder esses poderes (divinos) às organizações privadas ou às públicas? às empresas ou ao governo? Sua conclusão: a nenhum deles. A propriedade privada, do próprio titular dos dados, seria mais adequada (HARARI, 2018, p. 109-110). Em outras palavras, para o autor, a chamada autodeterminação informacional seria uma melhor opção.

Retomamos então mais uma ideia referenciada no início desta pesquisa. Mesmo a propriedade privada, enquanto expressão da autodeterminação informacional, parece inadequada à proteção da informação (em seu conceito aqui abordado), parecendo mais ade-

11 "Em março de 2018, uma reportagem do The Observer revelou que a empresa roubou os dados de 87 milhões de pessoas na rede social para influenciar resultados das eleições no País [Estados Unidos da America]." Fonte: ROMANI, Bruno. 'As pessoas foram enganadas para dar algo valioso: seus dados', diz Brittany Kaiser. Disponível em: https://link.estadao. com.br/noticias/cultura-digital,as-pessoas-foram-enganadas-para-dar-algo-valioso-seus-dados-diz-brittany-kaiser,70003275070 Acesso em: 15 de maio de 2020. 
quada, como a pesquisa de Sampaio (2019) nos leva a entender, uma proteção dela como um interesse metaindividual, pois seu uso inadequado, sua alocação em massa nas mãos de um ou outro, atingirá toda a coletividade, não sendo mais suficiente confiar sua proteção total a cada indivíduo. De outra forma, a Sociedade da Informação atual (apoiada pelas tecnologias) poderá colocar fim à democracia e dar início a um período de monopólio do poder (político, científico, genético, financeiro etc.) das gigantes da informação.

A temática foi abordada também por outros juristas, mas a doutrina ainda começa a desbravá-la. Pinho e Marca (2017, p. 287), ao abordarem a insuficiência da tutela individual para a proteção de dados atualmente, fundamentam a necessidade deste olhar coletivo, a priori, em questões voltadas ao consumo, exemplificando furto de dados ou o perfilamento para manipulação de consumo (prática anteriormente aqui referenciada como "consumidor de vidro"). Mas a verdade é que, como as ponderações de Harari indicam, os problemas vão muito além disso.

Caminhando um pouco mais à frente, Zanatta (2019, p. 202) trata da "coletivização da proteção de dados pessoais" (como chama), esclarecendo ser impossível exigir do titular dos dados a ciência de todas as relações comerciais firmadas, pois "a maioria dos dados que movem a economia digital não é cedida". Para o autor, a maioria dos dados é tomada dos dispositivos ou inferida a partir de padrões.

Além disso, o autor destaca quatro elementos básicos para tal coletivização. 0 primeiro considera a possibilidade de se observar violação aos valores da sociedade, ou seja, para além do indivíduo. 0 segundo, a forma pela qual a proteção deve ocorrer, apontando como meio principal as ações civis públicas. 0 terceiro elemento visa à proteção do ambiente informacional, impondo às empresas e órgãos do setor público que tratam dados a obrigação de avaliar o impacto de suas atividades e adotar medidas para evitar ou minimizar os possíveis danos. 0 último elemento apontado pelo autor diz respeito a encarar a proteção de dados pessoais como questão coletiva de defesa do consumidor (ZANATTA, 2019, p. 203).

Além dos elementos básicos, Zanatta (2019, p. 2014) destaca uma especificidade da proteção de dados no Brasil e aponta um quinto elemento. Segundo ele, a coletivização da proteção de dados em nosso ordenamento jurídico há de ser intensamente marcada pela atuação do Ministério Público.

Zanatta considera eventuais ameaças a valores sociais, além de tratar das relações consumeristas, nos permitindo nos aproximar um pouco mais da proteção que o cenário pede, mas ainda não considera o quadro total. Sampaio (2019, p. 50) trata do uso da informação, destacando que ele pode, inclusive, influenciar resultados eleitorais. 0 autor demonstra que o perfilamento utilizado nas práticas de marketing pode também ser utilizado para manipular escolhas eleitorais, nos encaminhando, em um nível nacional, talvez à maior problemática a ser enfrentada pelo sistema de proteção de dados atualmente, como alguns escândalos já demonstram.

Cumpre esclarecer, neste sentido, que esta afirmação, mesmo que possivelmente seja catastrófica, também pode ser um alento diante de riscos ainda mais sombrios. Isso porque essa ameaça à democracia, embora grave, não é diretamente o maior problema a combatermos com relação ao uso da informação. Sampaio fala do emprego das informações durante o período nazista, em que a "eugenia positiva" (a fecundidade "racialmente superior") foi 
suportada por dados coletados pelo governo, além de outros exemplos igualmente preocupantes, notadamente quanto à perseguição de minorias e violação de direitos humanos (SAMPAIO, 2019, p. 25). Mesmo que a ameaça à democracia seja manifesta e iminente, já carente de embates, a esperança é que não se vá além disso, que não voltemos a violar os direitos humanos como outrora e que esta seja a maior luta a travarmos. Que mantenhamos, ao menos, nossa humanidade, em detrimento da incessante aurora tecnológica à qual assistimos todos os dias.

Assim, é imprescindível que compreendamos o valor da informação na sociedade atual para que possamos alcançar as conclusões como as adotadas por Harari e Sampaio. A conceituação de "informação" e "Sociedade da Informação" se faz necessária para revelar de forma mais clara este cenário, mas é apenas o ponto de partida. 0 uso da informação tem se tornado cada vez mais controverso, atendendo às agendas pessoais e empresariais, violando direitos humanos individuais e metaindividuais, suscitando a necessidade de normas suficientes a resguardar tal padrão de direitos.

\section{CONCLUSÃO}

Este estudo se propôs a analisar e estabelecer, através de pesquisa bibliográfica, conceito para a "informação" no contexto da Sociedade da Informação e, considerando este, alcançar um conceito para a própria "Sociedade da Informação", tendo em vista a inexatidão que assola esses termos inclusive na comunidade acadêmica, o que dificulta o estudo desse campo. A pesquisa propõe uma análise não exaustiva e o sucinto apontamento da importância dessa matéria, tendo em vista sua necessária brevidade.

Assim, foi analisado referencial teórico acerca do conceito de "informação", que permitiu conhecer a classificação de três principais significados atribuídos a essa palavra, sendo eles: "informação como processo", "informação como conhecimento" e "informação como coisa", com cada uma das características que os diferenciam. Além disso, estudamos a chamada Hierarquia da Sabedoria, que esclarece a diferença funcional dos conceitos de "dados", "informação", "conhecimento" e "sabedoria", bem como a atribuição de valor a cada um deles.

Em uma análise da literatura sobre Sociedade da Informação, verificamos que informação se trata de recurso e produto para a indústria, agregando a produtos e serviços real valor econômico. E tal valor, que lhe é atribuído, depende do fator tempo. Além disso, estabelecemos que a informação possui um valor em potencial, isto é, ainda a se revelar.

Diante desta base referencial, estabelecemos um conceito complexo de informação para a Sociedade da Informação e, agora, o transcrevemos para que, no intuito de resumir as informações, não percamos relevantes fatores apontados nele: Informação é para a Sociedade da Informação uma entidade intangível, objeto de um processo informacional, comunicativo, que, em sentido lato, acolhe dados, informações, conhecimento e entendimento, na medida em que cada um destes termos possui a mesma estrutura, apesar de suas diferentes funções. A informação é recurso e produto final no processo produtivo, considerando-se que é utilizada para a produção de mais informação, tanto quanto é o resultado dessa produção. Possui valor mercadológico, financeiro, de forma independente, decorrente de sua 
capacidade de atribuir valor a produtos e serviços, o que pode ser aferido de formas diversas a depender do tempo de difusão. E possui um valor potencial, decorrente de seu uso futuro, ainda incerto na forma, mas certo no poder.

Diante disto, passamos à análise bibliográfica específica da Sociedade da Informação, no mesmo intuito de alcançar um conceito ao termo. Inicialmente, analisamos um breve contexto histórico que nos permitiu estabelecer que "Sociedade da Informação" referencia, inicialmente, a sociedade que tem a informação como produtora de valor econômico.

Considerando outras mais características que a doutrina reconhece à Sociedade da Informação, concluímos (e aqui novamente transcrevemos): Sociedade da Informação como sendo o momento histórico econômico-social em que a entidade intangível que é o objeto do processo comunicacional, isto é, a informação como conhecimento, é o meio e o fim das relações mercadológicas, pois ela se apresenta como recurso e como produto. Neste período, a informação é capaz de atribuir valor, que será cotejado de diferentes formas em diferentes contextos temporais, sendo que as relações (organizadas em rede), assim como a economia, passam a ter caráter global, cujas bases repousam nas novas tecnologias da informação.

Por fim, estabelecemos a importância de seu estudo, que se revela pelos incontáveis usos escusos que a informação pode e tem encontrado em nossa sociedade, concluindo que é necessário um novo marco regulatório para a Sociedade da Informação, supraindividual, para que ela não implique passos acerca dos quais, em que pese se arrepender, a sociedade nunca possa voltar atrás.

\section{REFERÊNCIAS}

AMARAL, Luís Mira. Economia tech: da indústria à sociedade da informação e do conhecimento. Lisboa, Booknomics, 2008.

ACKOFF, Russel. From Data to Wisdom. In Ackoff's Best, New York, John Wiley \& Sons, 1999, p. 170 - 172. Disponível em: http://faculty.ung.edu/kmelton/Documents/DataWisdom.pdf Acesso em 08 de abril de 2020.

BIONI, Bruno Ricardo. Proteção de dados pessoais: a função e os limites do consentimento. Rio de Janeiro, Forense, 2019.

BRANCO, Marcelo. Software Livre e Desenvolvimento Social e Económico. InA Sociedade em Rede Do Conhecimento à Acção Política. Portugal, Imprensa Nacional - Casa da Moeda, 2005, p. 227-236.

BUCKLAND, Michael K. Information as Thing. In Journal of the American Society for Information Science. Jun 1991; 42, 5, p. 351-360. Disponível em: https://cmapspublic.ihmc.us/rid=1KR7TY2LF-B4K41P-5SWT/ BUCKLAND(1991)-informationasthing.pdf Acesso em: 07 de abril de 2020.

CASTELLS, Manuel. A Sociedade em Rede. São Paulo, Paz\&Terra, 2016.

CASTELLS, Manuel. A Sociedade em Rede: do Conhecimento à Política. In A Sociedade em Rede Do Conhecimento à Acção Política. Portugal, Imprensa Nacional - Casa da Moeda, 2005, p. 17-30.

CRAWFORD, Susan. The Origin and development of a concept: The Information Society. In Bulletin of the Medical Library Association, oct 1983, p. 380-385. Disponível em: https://www.ncbi.nlm.nih.gov/pmc/articles/ PMC227258/?page=1Acesso em 09 de abril de 2020.

HARARI, Yuval Noah. 21 lições para o século 21. São Paulo, Companhia das Letras, 2018. 
HIMANEN, Pekka. Desafios Globais da Sociedade de Informação. InA Sociedade em Rede Do Conhecimento à Acção Política. Portugal, Imprensa Nacional - Casa da Moeda, 2005, p. 347-370.

KARVALICS, László Z. Information Society - what is it exactly? (The meaning, history and conceptual framework of an expression). Budapest, 2007, p. 05. Disponível em: http://citeseerx.ist.psu.edu/viewdoc/download?doi=10. 1.1.575.6057\&rep=rep1\&type=pdf Acesso em: 15 de maio de 2020.

LOVELUCK, Benjamin. Redes, liberdades e controle. Petrópolis, Vozes, 2018.

MASI, Domenico. A Sociedade Pós Industrial. 4 Ed., Senac São Paulo, São Paulo, 2003.

MATTELART, Armand. História da sociedade da informação. 2 ed. São Paulo: Edições Loyola, 2006.

PINHO, Humberto Dalla Bernardina; MARCA, Luiz Augusto Castello Branco de Lacerda. Possibilidades e limites para a tutela da intimidade e da privacidade enquanto direitos meta-individuais. In Revista Eletrônica de Direito Processual, n. Ano 11. Volume 18. Número 1. Janeiro a Abril de 2017, p. 278-301. Disponível em: https://www.e-publicacoes.uerj.br/index.php/redp/article/view/28492/20280 Acesso em 25 de maio de 2020.

ROMANI, Bruno. 'As pessoas foram enganadas para dar algo valioso: seus dados', diz Brittany Kaiser. Disponível em: https://link.estadao.com.br/noticias/cultura-digital,as-pessoas-foram-enganadas-para-dar-algo-valioso-seus-dados-diz-brittany-kaiser,70003275070 Acesso em: 15 de maio de 2020.

ROWLEY, Jennifer. The wisdom hierarchy: representations of the DIKW hierarchy. Jornal ofInformation Science, v.33, n.2, p. 163-180, 2006. Disponível em: https://journals.sagepub.com/doi/abs/10.1177/0165551506070706 Acesso em: 08 de abril de 2020.

SAMPAIO, Vinícius Garcia Ribeiro. Proteção de dados pessoais: da privacidade à tutela de interesses metaindividuais. Dissertação (mestrado em Direito). Centro Universitário das Faculdades Metropolitanas Unidas, São Paulo, 2019.

SARACEVIC, Tefko. Ciência da informação: origem, evolução e relações. In Ci. Inf., Belo Horizonte, v. 1, n. 1, p. 41-62, jan./jun. 1996. Disponível em: http://portaldeperiodicos.eci.ufmg.br/index.php/pci/article/view/235/22 Acesso em: 09 de abril de 2020.

TAKAHASHI, Tadao (org.). Sociedade da informação no Brasil: livro verde. Brasília: Ministério da Ciência e Tecnologia, 2000. Disponível em: https://www.ufmg.br/proex/cpinfo/cidadania/wp-content/uploads/2014/04/Livro-verde.pdf Acesso em: 09 de abril de 2020.

WEBSTER, Frank. Theories of the information society. 3 ed. Nova York: Routledge, 2006.

ZANATTA, Rafael A. F. A tutela coletiva na proteção de dados pessoais. Revista do Advogado: Lei Geral de Proteção de Dados Pessoais, n. 144, São Paulo: Associação dos Advogados de São Paulo, nov. 2019, p. 201-208.

Recebido/Received: 03.06.2020.

Aprovado/Approved: 12.10 .2020 